\title{
Porous Organic Polymer Synthesized by Green Diazo-Coupling Reaction for Adsorptive Removal of Methylene Blue
}

\author{
Yang Shen, Wen-Xin Ni, and Bing Li*
}

Cite This: ACS Omega 2021, 6, 3202-3208

Read Online

ABSTRACT: A porous organic polymer (marked as DT-POP), which contains abundant free phenolic hydroxyl groups, is synthesized by the well-known green azo-coupling reaction in water, characterized, and utilized as an effective adsorbent for the elimination of methylene blue (MB) from water solutions. The presence of permanent mesopores, abundant active functional groups, and $\pi$-electron enrichment ascribed to phenyl rings make DT-POP an efficient adsorbent for MB due to strong hydrogen bonding, $\pi-\pi$, and electrostatic interactions with the cationic dye MB. DT-POP with high stability and high adsorption capacity can be reused many times and thus shows high applicability in pollutant disposal.

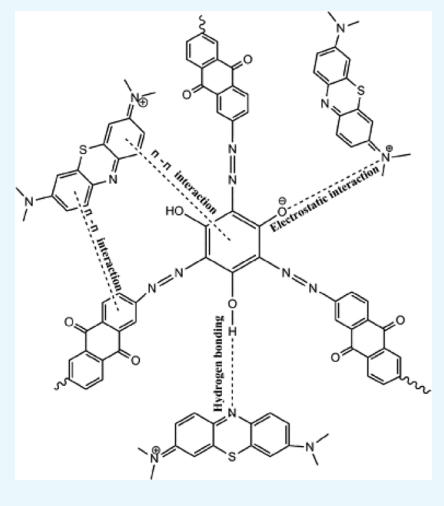

\section{INTRODUCTION}

The shortage and pollution of water resources have received extensive attention recently. Water pollution by the disposal of dyes, including methylene blue (MB), has an adverse impact on ecosystems and human health. ${ }^{1}$ Therefore, it is necessary to establish efficient techniques to remove dyes from contaminated water sources. Many techniques can be adopted for elimination of dyes from contaminated water, including membrane separation, biodegradation, and adsorption. ${ }^{2-4}$ Among these methods, adsorption is known as the easiest, most effective, and economical way for dye capture. The key feature of adsorption in treating wastewater is to choose suitable adsorbents. Hence, new adsorption materials with high adsorption capacity, low cost, high chemical stability, and easy regeneration are urgently demanded for dye removal.

Porous organic polymers (POPs), a novel type of porous substances built from organic monomers via polycondensation reaction to form covalent bonds, have attracted wide attention in the fields of gas storage, adsorption, and catalysis thanks to their low density, variable structures, high porosity, large specific surface areas, and excellent physicochemical stability. $^{5-10}$ Recently, POPs have become promising candidates for wastewater treatment. ${ }^{11-14}$ For example, Liu et al. ${ }^{11}$ synthesized through polycondensation two nitrogen-rich POPs for highly efficient adsorption of iodine. Most POPs are synthesized by condensation reactions, such as the Schiff base formation under organic solvents and high-temperature conditions. ${ }^{15-17}$ The diazo-coupling reaction is mild in aqueous solutions for the synthesis of POPs by the use of different monomers, such as tri/diamines and tri/diphenols. ${ }^{18-20}$ For example, Das and co-workers prepared a novel
POP based on the diazo-coupling reaction of 2,6,14triaminotriptycene with 1,4-dihydroxybenzene, and the POP can adsorb cationic $\mathrm{MB}$ with the capacity of $250 \mathrm{mg} \cdot \mathrm{g}^{-1} \cdot{ }^{19}$ However, the use of POP-based adsorbents to treat wastewater is still in its infancy. Thus, much work needs to be done, especially a systematic study of the adsorption process and mechanism.

Phloroglucinol with abundant hydroxyl groups is an inexpensive commercial reagent, and 2,6-diaminoanthraquinone is an aromatic compound containing diamine. Here, an azo-based porous POP (marked as DT-POP) was conveniently synthesized by the diazo-coupling of two monomers in aqueous solutions under mild conditions and used as an adsorbent to investigate the adsorption performance and mechanism toward MB.

\section{RESULTS AND DISCUSSION}

2.1. Characterization of DT-POP. The FT-IR spectra of DT-POP with and without adsorption of $\mathrm{MB}$ are displayed in Figure $1 \mathrm{a}$. The wide adsorption band at $3426 \mathrm{~cm}^{-1}$ comes from -OH stretching vibration. ${ }^{18,20}$ The peaks at 1295 and 1672 $\mathrm{cm}^{-1}$ stand for the stretching vibrations of $\mathrm{C}-\mathrm{N}$ and $\mathrm{C}=\mathrm{O}$, respectively. ${ }^{18}$ The peak at $1588 \mathrm{~cm}^{-1}$ corresponds to $\mathrm{C}=\mathrm{C}^{21}$ The peak at $1476 \mathrm{~cm}^{-1}$ is caused by the asymmetric vibrating

Received: November 18, 2020

Accepted: January 11, 2021

Published: January 20, 2021 

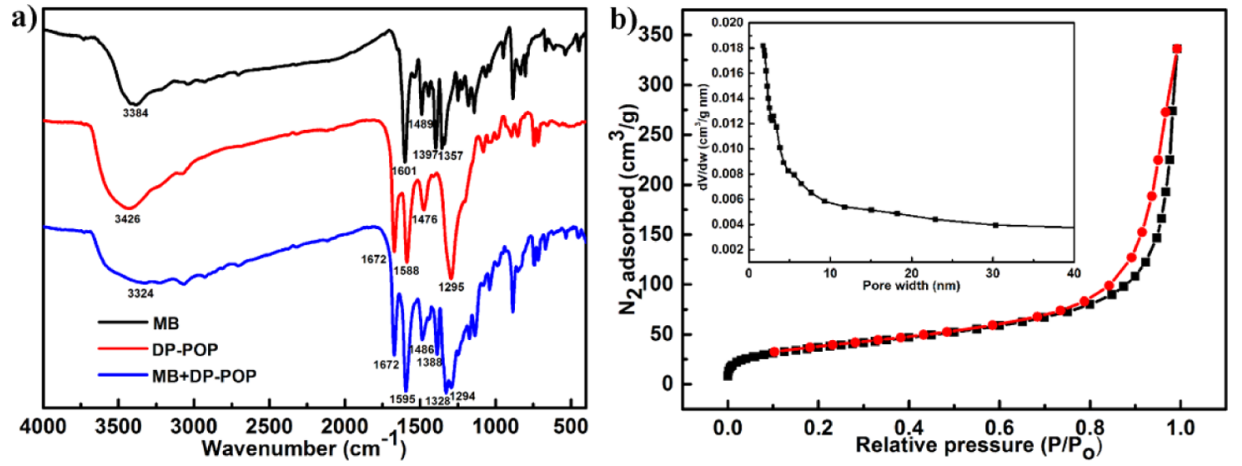

Figure 1. (a) FT-IR spectra of the samples. (b) $\mathrm{N}_{2}$ adsorption-desorption isotherms and pore size distribution (inset) of DT-POP.

a)

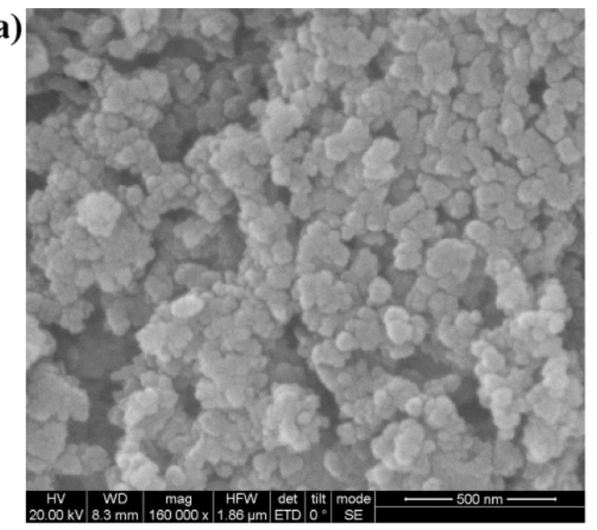

c)

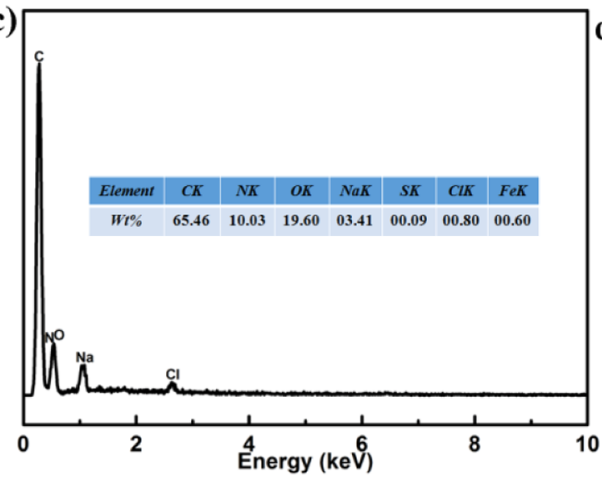

b)
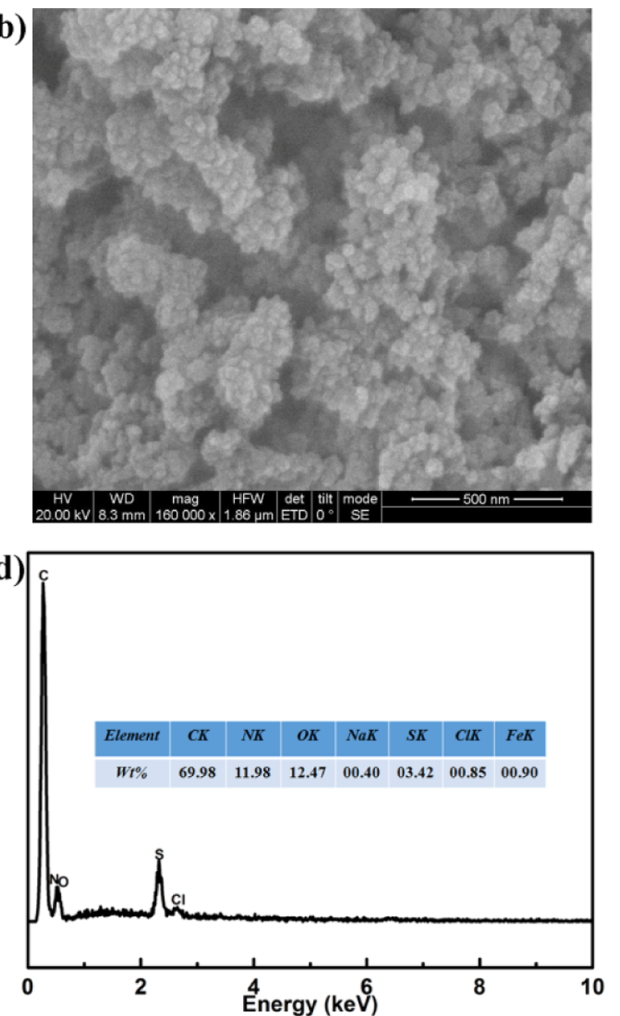

Figure 2. SEM images/EDS spectra of DT-POP without (a,c) and with (b,d) adsorption of MB.

of $\mathrm{N}=\mathrm{N}$, indicating that the coupling reaction occurred and the framework structure of DT-POP was formed. ${ }^{18}$ After adsorption of $\mathrm{MB}$, the adsorption bands at 1595, 1388, and $1328 \mathrm{~cm}^{-1}$ stand, respectively, for the stretching vibrations of $\mathrm{C}=\mathrm{N}, \mathrm{C}-\mathrm{N}$, and the $-\mathrm{CH}_{3}$ symmetric deformation from $\mathrm{MB}$ which also appears. ${ }^{22}$ These characteristic peaks indicate that $\mathrm{MB}$ is adsorbed on DT-POP. The stretching vibration of $-\mathrm{OH}$ in DT-POP is obviously red-shifted and widened after adsorption, indicating that there is a hydrogen bond formation between the phenolic hydroxyl of DT-POP and the nitrogen atom in phenothiazine of $\mathrm{MB} \cdot{ }^{12,20}$ The $\mathrm{C}-\mathrm{N}$ stretching vibrating of $-\mathrm{N}\left(\mathrm{CH}_{3}\right)_{2}$ and the $-\mathrm{CH}_{3}$ symmetric deformation vibration at 1397 and $1357 \mathrm{~cm}^{-1}$ in $\mathrm{MB}$ were red-shifted, and sodium element content in DT-POP decreased after adsorption, as revealed by energy-dispersive $\mathrm{X}$-ray spectroscopy (EDS). These results verify that $-\mathrm{N}\left(\mathrm{CH}_{3}\right)_{2}{ }^{+}$of $\mathrm{MB}$ can electrostatically interact with phenolate of DT-POP. ${ }^{4}$ The stretching vibration of $\mathrm{C}=\mathrm{C}$ and $\mathrm{N}=\mathrm{N}$ in DT-POP migrated from 1588 to $1595 \mathrm{~cm}^{-1}$ and 1476 to $1486 \mathrm{~cm}^{-1}$ after MB adsorption, respectively. These changes may be attributed to $\pi-\pi$ interaction in MB and DT-POP during the adsorption. ${ }^{29}$

The isotherm of DT-POP was detected by $\mathrm{N}_{2}$ ad/desorption analysis at $77 \mathrm{~K}$ (Figure $1 \mathrm{~b}$ ). DT-POP exhibits a typical IV pattern, indicating the presence of mesopores in DT-POP. The pore size layout curve (inset in Figure 1b) clearly validates its mesoporous structure. The Brunauer-Emmett-Teller (BET) specific surface area of DT-POP is slightly smaller than a reported value $\left(133.87\right.$ vs $\left.192.93 \mathrm{~m}^{2} \cdot \mathrm{g}^{-1}\right) .{ }^{18}$ However, the Barrett-Joyner-Halenda (BJH) adsorption cumulative volume is slightly larger than a reported value $\left(0.51 \mathrm{vs} 0.41 \mathrm{~cm}^{3}\right.$. g).

The morphology of DT-POP before and after adsorption was characterized by scanning electron microscopy (SEM)EDS (Figure 2). The images showed an amorphous agglomerate morphology and no remarkable differences in morphology or size for both samples (Figure 2a,b). After adsorption, the sulfur element content increased obviously from the EDS data (Figure $2 \mathrm{c}, \mathrm{d}$ ), indicating that $\mathrm{MB}$ was 

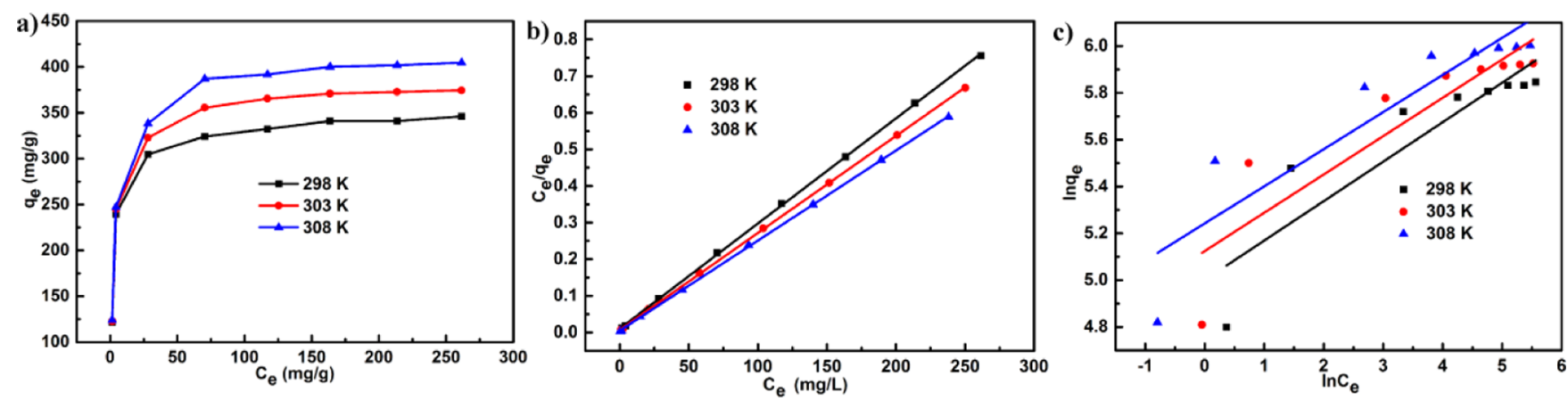

Figure 3. (a) Adsorption isotherms of MB onto DT-POP. Linear fitting of equilibrium adsorption data with (b) Langmuir and (c) Freundlich equations. $\left(m=10 \mathrm{mg} ; V=25 \mathrm{~mL} ; C_{\mathrm{o}}=50-400 \mathrm{mg} \cdot \mathrm{L}^{-1} ; t=8 \mathrm{~h} ; T=298,303\right.$ and $\left.308 \mathrm{~K}\right)$.

Table 1. Parameters of Langmuir and Freundlich Equations for MB on DT-POP

\begin{tabular}{|c|c|c|c|c|c|c|c|}
\hline \multirow[b]{2}{*}{$T(\mathrm{~K})$} & \multirow[b]{2}{*}{$q_{\mathrm{e}}(\exp )$} & \multicolumn{3}{|c|}{ Langmuir model } & \multicolumn{3}{|c|}{ Freundlich model } \\
\hline & & $Q_{0}\left(\mathrm{mg} \cdot \mathrm{g}^{-1}\right)$ & $b\left(\mathrm{~L} \cdot \mathrm{mg}^{-1}\right)$ & $R^{2}$ & $K_{\mathrm{F}}$ & $1 / n$ & $R^{2}$ \\
\hline 298 & 346.10 & 348.43 & 0.2719 & 0.99974 & 148.46 & 0.16865 & 0.78461 \\
\hline 303 & 374.56 & 377.36 & 0.3829 & 0.99990 & 168.02 & 0.16375 & 0.77040 \\
\hline 308 & 404.66 & 406.50 & 0.5041 & 0.99987 & 189.09 & 0.15862 & 0.80510 \\
\hline
\end{tabular}

adsorbed on the surface of DT-POP. The powder X-ray diffraction (PXRD) patterns further confirmed the amorphous structure of DT-POP (Figure S1a).

The thermal stability of DT-POP was tested by thermogravimetric analysis (TGA). DT-POP has high thermal stability from the TGA curve (Figure S1b) and only about $12 \%$ of weight was lost at $200{ }^{\circ} \mathrm{C}$, which was probably ascribed to the loss of solvent molecules in the pores of DT-POP. Its weight loss rate was rapid from 200 to $400{ }^{\circ} \mathrm{C}$ and then dropped sharply after $400{ }^{\circ} \mathrm{C}$, which may be due to the degradation of the DT-POP skeleton and partial carbonization. Its thermal stability is similar to that reported in the literature. $^{18}$

2.2. Adsorption Isotherms. The adsorption isotherms (Figure 3a) showed that the adsorbing ability of DT-POP for $\mathrm{MB}$ was strengthened rapidly and then slowly increased to a plateau with the rise of $\mathrm{MB}$ concentration, indicating that increase in concentration within a certain range promoted the increase of adsorption capacity. To clarify the adsorbing performance of $\mathrm{MB}$ onto DT-POP, we described the adsorption procedure by classic Langmuir (eq 1) and Freundlich (eq 2) equations. ${ }^{23,24}$

$$
\begin{aligned}
& \frac{C_{\mathrm{e}}}{q_{\mathrm{e}}}=\frac{C_{\mathrm{e}}}{Q_{\mathrm{o}}}+\frac{1}{b Q_{\mathrm{o}}} \\
& \ln q_{\mathrm{e}}=\ln K_{\mathrm{F}}+\frac{1}{n} \ln C
\end{aligned}
$$

where $Q_{0}\left(\mathrm{mg} \cdot \mathrm{g}^{-1}\right)$ and $q_{\mathrm{e}}\left(\mathrm{mg} \cdot \mathrm{g}^{-1}\right)$ represent the theoretical maximal quantity and actual adsorbed quantity of MB on DTPOP, respectively; $C_{\mathrm{e}}\left(\mathrm{mg} \cdot \mathrm{L}^{-1}\right)$ represents the final $\mathrm{MB}$ concentration in solution under equilibrium; $b\left(\mathrm{~L} \cdot \mathrm{mg}^{-1}\right)$ and $K_{\mathrm{F}}\left(\mathrm{mg}^{1-1 / n} \mathrm{~L}^{1 / n} \mathrm{~g}^{-1}\right)$ stand for the constants of the two models, respectively; and $n$ is adsorption intensity of $\mathrm{MB}$ on DT-POP at an equilibrium state.

The fitting curves by the two models are shown in Figure $3 b, c$, and the relevant indices are summarized in Table 1 . Clearly, the adsorption isotherms are more in line with the Langmuir equation due to the larger correlation coefficient
$\left(R^{2}\right)$ (Table 1$)$, indicating that the absorption of MB by DTPOP belongs to the monolayer coverage.

The $Q_{0}$ computed by the Langmuir model is $348.43 \mathrm{mg} \cdot \mathrm{g}^{-1}$ at $298 \mathrm{~K}$, indicating that DT-POP is an excellent adsorbent for MB. Table 2 compares the adsorbing ability of DT-POP with

Table 2. Adsorption Capacity of DT-POP and Other Reported Adsorbents

\begin{tabular}{lcl}
\multicolumn{1}{c}{ adsorbents } & $\begin{array}{c}\text { adsorption capacity } \\
\left(\mathrm{mg} \mathrm{g}^{-1}\right)\end{array}$ & references \\
$\begin{array}{lcl}\text { triptycene based-hydroxyl-azo-polymer } \\
\text { bifunctional anionic metal-organic } \\
\quad \text { framework }\end{array}$ & 250 & 12 \\
$\begin{array}{l}\text { melamine-formaldehyde-tartaric acid } \\
\text { resin }\end{array}$ & 60.6 & 25 \\
porous poly(imide-ether)s & 169.8 & 27 \\
TPT-DMBD-COF & 45.45 & 28 \\
tannin-based magnetic POPs & 1832 & 29 \\
DT-POP & 346.1 & this study \\
\hline
\end{tabular}

other adsorbents. The uptake capacity of DT-POP is higher than that of most other reported adsorbents. In addition, $Q_{0}$ increases from 348.43 at $298 \mathrm{~K}$ to $406.50 \mathrm{mg} \cdot \mathrm{g}^{-1}$ at $308 \mathrm{~K}$, suggesting that the adsorption of MB on DT-POP is favorable at high temperatures.

2.3. Adsorption Thermodynamics of DT-POP for MB. The thermodynamic parameters $(\Delta G, \Delta H$, and $\Delta S)$ of $\mathrm{MB}$ adsorbed onto DT-POP were determined from the isotherms data by eqs 3 and $4^{4,30}$

$$
\begin{aligned}
& \Delta G^{\mathrm{o}}=-R T \ln b \\
& \ln b=\frac{\Delta S^{\mathrm{o}}}{R}-\frac{\Delta H^{\mathrm{o}}}{R T}
\end{aligned}
$$

The results are listed in Table 3. Adsorption of $\mathrm{MB}$ onto DT-POP is spontaneous due to the negative $\Delta G$. The $\Delta S$ is $252.80 \mathrm{~J} \cdot \mathrm{mol}^{-1} \cdot \mathrm{K}^{-1}$, which is favorable for adsorption due to the increase of randomness during the adsorption. The positive $\Delta H$ indicates that the adsorption is endothermic, as revealed 
Table 3. Thermodynamic Parameters of MB Adsorption onto DT-POP

$\begin{array}{ccccc}T(\mathrm{~K}) & \Delta G\left(\mathrm{~kJ} \cdot \mathrm{mol}^{-1}\right) & \Delta H\left(\mathrm{~kJ} \cdot \mathrm{mol}^{-1}\right) & \Delta S\left(\mathrm{~J} \cdot \mathrm{mol}^{-1} \cdot \mathrm{K}^{-1}\right) & R^{2} \\ 298 & -28.18 & 47.132 & 252.80 & 0.99431 \\ 303 & -29.51 & & & \\ 308 & -30.71 & & & \end{array}$

by the increase of adsorption capacity with the temperature rise.

2.4. Adsorption Kinetics. The adsorption kinetics of $M B$ on DT-POP was investigated by exploring the influence of contact time (Figure 4). The adsorption capacity of DT-POP enhanced quickly at first and then rose slowly until balancing because the adsorbing positions were slowly taken by MB with the prolonging of contact time (Figure $4 \mathrm{a}$ ). The adsorption was balanced after $120 \mathrm{~min}$.

To further understand the kinetic mechanism, we fitted the kinetic data by using the pseudo-2nd-order (eq 5) and pseudo1 st-order (eq 6) equations. ${ }^{31-33}$

$$
\begin{aligned}
& \frac{t}{q_{t}}=\frac{t}{q_{\mathrm{e}}}+\frac{1}{k_{2} q_{\mathrm{e}}^{2}} \\
& \ln \left(q_{\mathrm{e}}-q_{t}\right)=\ln q_{\mathrm{e}}-k_{1} t
\end{aligned}
$$

where $q_{\mathrm{e}}$ and $q_{t}\left(\mathrm{mg} \cdot \mathrm{g}^{-1}\right)$ represent the quantities adsorbed under balance and at time $t$, respectively; and $k_{2}\left(\mathrm{~g} \mathrm{mg}^{-1}\right.$. $\left.\min ^{-1}\right)$ and $k_{1}\left(\mathrm{~min}^{-1}\right)$ represent the constants of the two models, respectively.

The fitting plots and corresponding parameters from both models were displayed in Figure $4 b, c$ and Table 4. Results showed that eq 4 better described $\mathrm{MB}$ adsorption onto the DT-POP due to the higher $R^{2}$. Moreover, the $q_{\mathrm{e}}$ (cal.) $(317.46$ $\left.\mathrm{mg} \cdot \mathrm{g}^{-1}\right)$ computed by eq 4 is also closer to the experimental $q_{\mathrm{e}}(\exp )\left(307.28 \mathrm{mg} \cdot \mathrm{g}^{-1}\right)$.

2.5. Effect of $\mathrm{pH}$ and Ionic Strength. To clarify the adsorption mechanism, we studied the zeta potential of DTPOP and adsorption capacity for $\mathrm{MB}$ at different $\mathrm{pHs}$. The adsorption capacity of MB on DT-POP was enhanced rapidly with an increment from $\mathrm{pH} 2$ to 4 and slightly climbed with a rise of $\mathrm{pH}$ (Figure 5a). The zeta potential of DT-POP dropped from +11.7 to $-35.7 \mathrm{mV}$ with the $\mathrm{pH}$ increasing from 2 to 12 (Figure $5 b$ ). The surface of DT-POP is positively charged at $\mathrm{pH} \mathrm{2,} \mathrm{which} \mathrm{is} \mathrm{unfavorable} \mathrm{for} \mathrm{the} \mathrm{adsorption} \mathrm{of} \mathrm{cationic} \mathrm{MB}$ because of the same charge repulsion. However, the large adsorbing ability for $\mathrm{MB}$ at $\mathrm{pH} 2$ implies that electrostatic interaction is not the only mechanism. ${ }^{20}$
Figure 6a displays the influence of ionic strength on the $\mathrm{MB}$ adsorption onto DT-POP in varying contents of $\mathrm{NaCl}$ solution. The adsorption capacity at $0.15 \mathrm{M} \mathrm{NaCl}$ remains up to $89.6 \%$ of that without $\mathrm{NaCl}$. In other words, the effect of salt concentration on adsorption is very weak, indicating that ion exchange is not the main adsorption mechanism. ${ }^{29}$

2.6. Regeneration of DT-POP. To test whether DT-POP can be regenerated, we carried out four adsorption-desorption cycles (Figure $6 \mathrm{~b}$ ). Results showed that the adsorbing capacity of the second cycle was less than that of pristine DT-POP and then a slow decrease of adsorption capacity was found in the following second cycles. The reusability experiments prove that DT-POP has high stability and can be reused for many cycles.

\section{CONCLUSIONS}

DT-POP containing phenolic $(-\mathrm{OH})$ and azo $(\mathrm{N}=\mathrm{N})$ moieties was successfully prepared by diazo-coupling reaction using water as a solvent under mild conditions. DT-POP showed excellent stability in water under different $\mathrm{pHs}$, large specific surface area, with mesopores and abundant functional groups, which make it an excellent adsorbent with high recyclability and uptake capacity for the elimination of cationic MB from water solutions. The high adsorbing performance depends mainly on the strong hydrogen bonding between the phenolic $-\mathrm{OH}$ of DT-POP and nitrogen atom of $\mathrm{MB}$, and $\pi-\pi$ interaction of DT-POP and MB. Overall, DT-POP is potentially a versatile adsorbent that is applicable in environmental repair.

\section{MATERIALS AND METHODS}

4.1. Materials. All chemicals were directly used from commercial sources: phloroglucinol $(\geq 99.0 \%)$ and 2,6diaminoanthraquinone (97\%) (both Aladdin) and $\mathrm{NaNO}_{2}$ ( $\geq 99.0 \%), \mathrm{Na}_{2} \mathrm{CO}_{3}$ ( $\left.\geq 99.8 \%\right), \mathrm{HCl}(36.0-38.0 \%), \mathrm{NaOH}$ ( $\geq 96.0 \%)$, methanol ( $\geq 99.5 \%)$, and MB (Ind) (all Sinopharm, Shanghai, China).

The stock solution of MB was made by dissolving an appropriate quantity of $\mathrm{MB}$ in deionized water and was diluted to prepare solutions at the desired concentrations.

4.2. Synthesis of DT-POP. The DT-POP was prepared by the diazo-coupling reaction according to a reported procedure with minor modification. ${ }^{18}$ Typically, $3.574 \mathrm{~g}$ of 2,6diaminoanthraquinone $(1.5 \mathrm{mmol})$ was added into a blend of concentrated hydrochloric acid $(60 \mathrm{~mL})$ and deionized water $(50 \mathrm{~mL})$ in a $2 \mathrm{~L}$ beaker and magnetically stirred at $0-5$ ${ }^{\circ} \mathrm{C}$ for $20 \mathrm{~min}$. Then the solution containing deionized water $(300 \mathrm{~mL})$ and sodium nitrite $(3.1 \mathrm{mmol}, 2.140 \mathrm{~g})$ was slowly
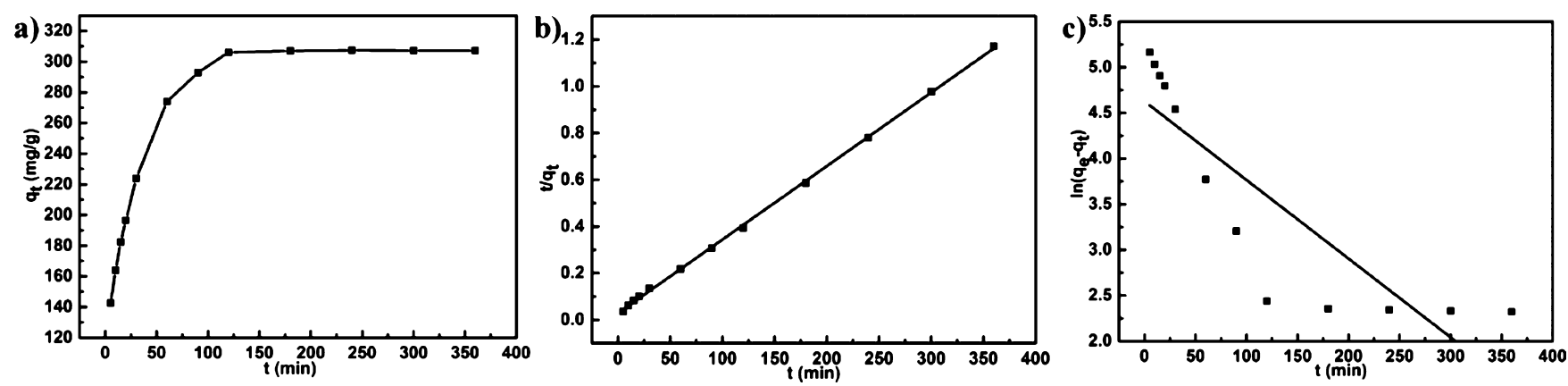

Figure 4. (a) Adsorption uptake of MB versus contact time. Fitting plots of (b) pseudo-second-order and (c) pseudo-first-order kinetic equations. $\left(m=10 \mathrm{mg} ; V=25 \mathrm{~mL} ; C_{\mathrm{o}}=150 \mathrm{mg} \cdot \mathrm{L}^{-1} ; \mathrm{T}=298 \mathrm{~K}, t=5-360 \mathrm{~min}\right)$. 
Table 4. Parameters of Two Kinetic Models for MB onto DT-POP

\begin{tabular}{|c|c|c|c|c|c|c|c|}
\hline \multirow[b]{2}{*}{$T(\mathrm{~K})$} & \multirow[b]{2}{*}{$q_{\mathrm{e}}(\exp )$} & \multicolumn{3}{|c|}{ pseudo-first-order } & \multicolumn{3}{|c|}{ pseudo-second-order } \\
\hline & & $\mathrm{q}_{\mathrm{e}}(\mathrm{cal}).\left(\mathrm{mg} \cdot \mathrm{g}^{-1}\right)$ & $k_{1}\left(\min ^{-1}\right)$ & $R^{2}$ & $\mathrm{q}_{\mathrm{e}}(\mathrm{cal}).\left(\mathrm{mg} \cdot \mathrm{g}^{-1}\right)$ & $k_{2}\left(\mathrm{mg} \cdot \mathrm{g}^{-1} \cdot \mathrm{min}^{-1}\right)$ & $R^{2}$ \\
\hline 298 & 307.28 & 102.26 & 0.00862 & 0.72962 & 317.46 & $3.467 \times 10^{-4}$ & 0.99949 \\
\hline
\end{tabular}
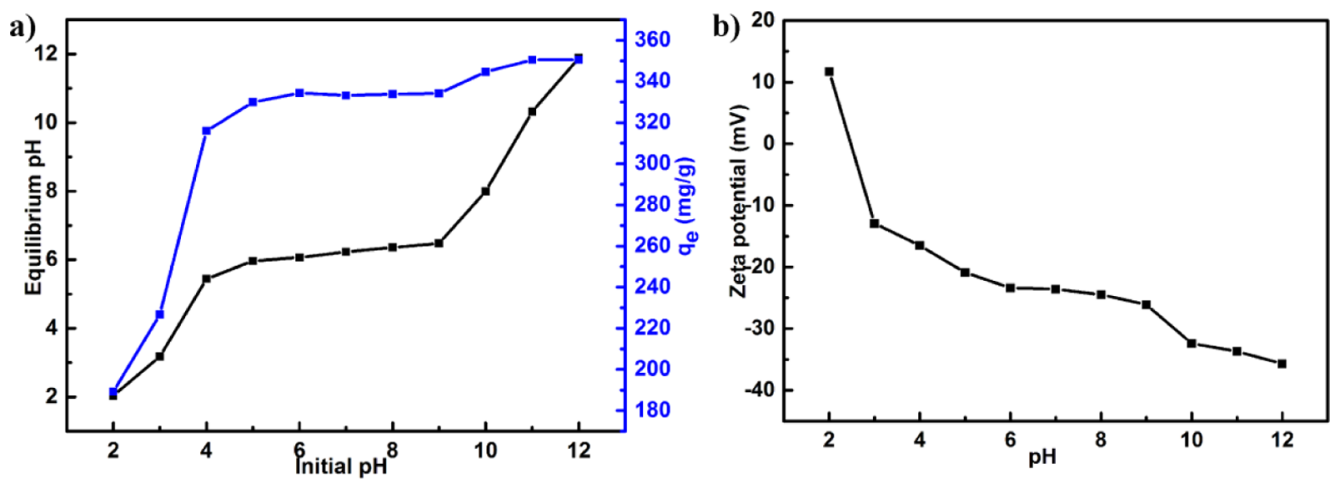

Figure 5. (a) Effect of $\mathrm{pH}$ on adsorption capacity; (b) zeta potential of DT-POP at varying $\mathrm{pH}\left(m=10 \mathrm{mg} ; V=25 \mathrm{~mL} ; C_{\mathrm{o}}=150 \mathrm{mg} \cdot \mathrm{L}^{-1} ; h=3 \mathrm{~h}\right.$; $T=298 \mathrm{~K} ; \mathrm{pH}=2-10)$.
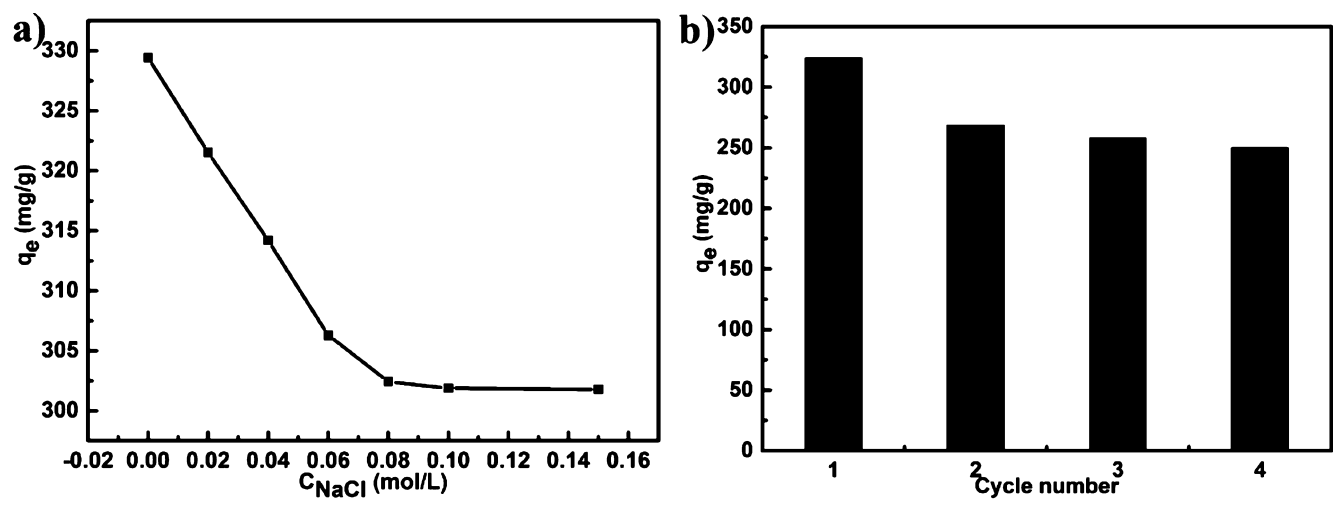

Figure 6. (a) Effect of $\mathrm{NaCl}$ concentration on uptake quantity, (b) adsorption capacity of $\mathrm{MB}$ onto DT-POP for several adsorption-desorption cycles $\left(\mathrm{m} / \mathrm{V}=0.4 \mathrm{~g} \cdot \mathrm{L}^{-1} ; V=25 \mathrm{~mL} ; C_{\mathrm{o}}=150 \mathrm{mg} \cdot \mathrm{L}^{-1} ; h=8 \mathrm{~h} ; \mathrm{T}=298 \mathrm{~K}\right)$.

Scheme 1. Synthesis Route of DT-POP

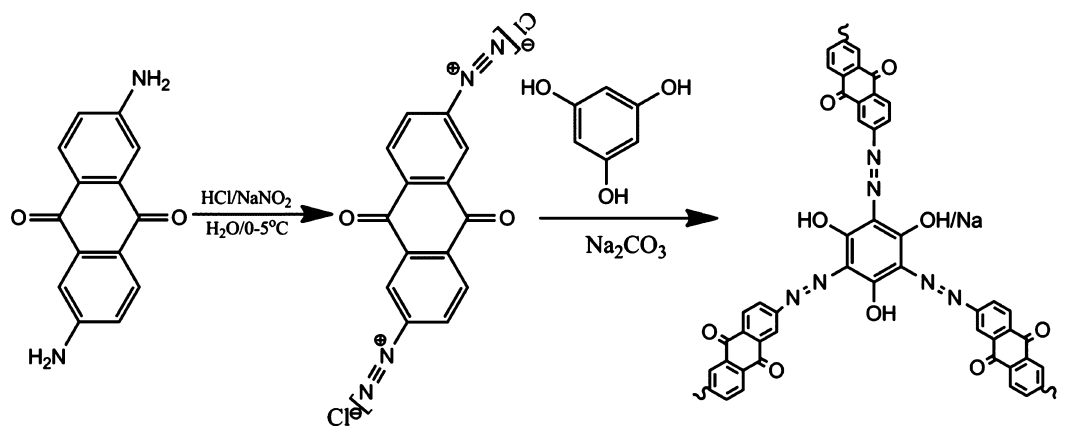

added into the above solution under an ice bath. Next, the mixture was adjusted to neutral $\mathrm{pH}$ by adding $950 \mathrm{~mL}$ of sodium carbonate $(80 \mathrm{~g})$ solution. Finally, $300 \mathrm{~mL}$ of a solution composed of $1.262 \mathrm{~g}$ of 1,3,5-trihydroxybenzene (1.0 $\mathrm{mmol}$ ) and $3.160 \mathrm{~g}$ of sodium carbonate $(3.0 \mathrm{mmol})$ was slowly dropped into the above solution under stirring below 5 ${ }^{\circ} \mathrm{C}$. A sepia powder was acquired by filtration, washed with deionized water, tetrahydrofuran, and deionized water, stirred for another $12 \mathrm{~h}$ at ambient temperature, and freeze-dried. The synthetic process for the DT-POP is illustrated in Scheme 1.
4.3. Instruments and Characterization Methods. PXRD was observed by a Bruker D8 XRD instrument. TGA was performed on a Universal V4.5A TA Instruments device at a heating speed of $10{ }^{\circ} \mathrm{C} \cdot \mathrm{min}^{-1}$ with nitrogen protection. The surface morphology and element analysis of DT-POP before and after adsorption were obtained on a SEM instrument (FEI, Quanta 400) containing an EDS detector. The porosity of DTPOP was measured by using the $\mathrm{N}_{2}$ adsorption-desorption isotherms with a Quantachrome Autosorb iQ2 analyzer at 77 $\mathrm{K}$. The $\mathrm{BJH}$ pore size layout and BET specific surface area 
were detected. Fourier transform infrared (FT-IR) spectra were observed using a Nicolet 8700 spectrometer.

4.4. Adsorption and Regeneration Experiments. The batch adsorption of MB on DT-POP was tested in triplicate by putting DT-POP $(10 \mathrm{mg})$ into an $\mathrm{MB}$ solution $(25 \mathrm{~mL})$ shaken at the rate of $110 \mathrm{rpm}$ in a thermostatic bath. After adsorption, the samples were filtered with $0.22 \mu \mathrm{m}$ filter membranes and the remaining $\mathrm{MB}$ content in the filtrate was tested by a UV-1100 spectrophotometer (Shanghai Meipuda Instrument Co., Ltd, Shanghai) at $665 \mathrm{~nm}$. The uptake amount $\left(q_{\mathrm{e}}, \mathrm{mg} \cdot \mathrm{g}^{-1}\right)$ of MB by DT-POP can be calculated as follows ${ }^{34}$

$$
q_{\mathrm{e}}=\frac{\left(C_{\mathrm{o}}-C_{\mathrm{e}}\right) V}{m}
$$

where $C_{\mathrm{o}}$ and $C_{\mathrm{e}}\left(\mathrm{mg} \cdot \mathrm{L}^{-1}\right)$ mean the original and final at equilibrium $\mathrm{MB}$ concentrations in the solution, respectively; and $m(\mathrm{mg})$ and $V(\mathrm{~mL})$ stand for the mass of DT-POP and the volume of solution, respectively.

Adsorption isotherms were separately obtained at 25, 30, and $35{ }^{\circ} \mathrm{C}$ for $8 \mathrm{~h}$ with $50-400 \mathrm{mg} \cdot \mathrm{L}^{-1}$ initial $\mathrm{MB}$ concentrations.

Adsorption kinetics experiments were carried out at varying time intervals with initially $150 \mathrm{mg} \cdot \mathrm{L}^{-1} \mathrm{MB}$ at $25^{\circ} \mathrm{C}$.

To study the effect of $\mathrm{pH}$ on $\mathrm{MB}$ adsorption onto DT-POP, we adjusted the initial $\mathrm{pH}$ of the $\mathrm{MB}$ solution $\left(150 \mathrm{mg} \cdot \mathrm{L}^{-1}\right)$ from 2 to 12 by diluting with $\mathrm{NaOH}$ or $\mathrm{HCl}$ solutions.

The regeneration of DT-POP was further evaluated by using ethanol/ $\mathrm{HCl}(1 \mathrm{M})(3: 1)$ solution as the eluent to remove MB from the MB-loaded DT-POP. In each cycle, both adsorption and desorption were carried out at $25{ }^{\circ} \mathrm{C}$ for $3 \mathrm{~h}$, and the solid-liquid ratio was $0.4 \mathrm{~g} \cdot \mathrm{L}^{-1}$.

\section{ASSOCIATED CONTENT}

\section{SI Supporting Information}

The Supporting Information is available free of charge at https://pubs.acs.org/doi/10.1021/acsomega.0c05634.

XRD patterns and TG curve of DT-POP (PDF)

\section{AUTHOR INFORMATION}

\section{Corresponding Author}

Bing Li - Zhejiang Provincial Key Laboratory of Chemical Utilization of Forestry Biomass, Zhejiang A\& F University, Hangzhou, Zhejiang 311300, P. R. China; (1) orcid.org/ 0000-0002-2432-1103; Email: libingzjfc@163.com

\section{Authors}

Yang Shen - Zhejiang Provincial Key Laboratory of Chemical Utilization of Forestry Biomass, Zhejiang A\&F University, Hangzhou, Zhejiang 311300, P. R. China

Wen-Xin Ni - Zhejiang Provincial Key Laboratory of Chemical Utilization of Forestry Biomass, Zhejiang A\& F University, Hangzhou, Zhejiang 311300, P. R. China

Complete contact information is available at:

https://pubs.acs.org/10.1021/acsomega.0c05634

\section{Notes}

The authors declare no competing financial interest.

\section{ACKNOWLEDGMENTS}

This work was supported by the National Natural Science Foundation of China (no. U1932126).

\section{REFERENCES}

(1) Adomas, B.; Sikorski, Ł.; Bęś, A.; Warmiński, K. Exposure of Lemna minor L. to gentian violet or Congo red is associated with changes in the biosynthesis pathway of biogenic amines. Chemosphere 2020, 254, 126752

(2) Varjani, S.; Rakholiya, P.; Ng, H. Y.; You, S.; Teixeira, J. A. Microbial degradation of dyes: An overview. Bioresour. Technol. 2020, 314, 123728.

(3) Yang, C.; Xu, W.; Nan, Y.; Wang, Y.; Chen, X. Novel negatively charged nanofiltration membrane based on 4,4'-diaminodiphenylmethane for dye removal. Sep. Purif. Technol. 2020, 248, 117089.

(4) Li, B.; Lv, J.-Q.; Guo, J.-Z.; Fu, S.-Y.; Guo, M.; Yang, P. The polyaminocarboxylated modified hydrochar for efficient capturing methylene blue and $\mathrm{Cu}$ (II) from water. Bioresour. Technol. 2019, 275, 360-367.

(5) Qi, S.-C.; Yu, G.-X.; Xue, D.-M.; Liu, X.; Liu, X.-Q.; Sun, L.-B. Rigid supramolecular structures based on flexible covalent bonds: A fabrication mechanism of porous organic polymers and their $\mathrm{CO}_{2}$ capture properties. Chem. Eng. J. 2020, 385, 123978.

(6) Nasrallah, H.; Hierso, J.-C. Porous materials based on 3dimensional td-directing functionalized adamantane scaffolds and applied as recyclable catalysts. Chem. Mater. 2019, 31, 619-642.

(7) Wang, S.; Hu, Q.; Liu, Y.; Meng, X.; Ye, Y.; Liu, X.; Song, X.; Liang, Z. Multifunctional conjugated microporous polymers with pyridine unit for efficient iodine sequestration, exceptional tetracycline sensing and removal. J. Hazard. Mater. 2020, 387, 121949.

(8) Gan, S.; Tong, X.; Zhang, Y.; Wu, J.; Hu, Y.; Yuan, A. Covalent Organic Framework-Supported Molecularly ispersed Near-Infrared Dyes Boost Immunogenic hototherapy against Tumors. Adv. Funct. Mater. 2019, 29, 1902757.

(9) Samui, A.; Kesharwani, N.; Haldar, C.; Sahu, S. K. Fabrication of nanoscale covalent porous organic polymer: An efficacious catalyst for Knoevenagel condensation. Microporous Mesoporous Mater. 2020, 299, 110112.

(10) Gu, C.; Hosono, N.; Zheng, J.-J.; Sato, Y.; Kusaka, S.; Sakaki, S.; Kitagawa, S. Design and control of gas diffusion process in a nanoporous soft crystal. Science 2019, 363, 387-391.

(11) Liu, C.; Xia, M.; Zhang, M.; Yuan, K.; Hu, F.; Yu, G.; Jian, X. One-pot synthesis of nitrogen-rich aminal- and triazine-based hierarchical porous organic polymers with highly efficient iodine adsorption. Polymer 2020, 194, 122401.

(12) Ansari, M.; Alam, A.; Bera, R.; Hassan, A.; Goswami, S.; Das, N. Synthesis, characterization and adsorption studies of a novel triptycene based hydroxyl azo- nanoporous polymer for environmental remediation. J. Environ. Chem. Eng. 2020, 8, 103558.

(13) Sun, Q.; Aguila, B.; Song, Y.; Ma, S. Tailored Porous Organic Polymers for Task-Specific Water Purification. Acc. Chem. Res. 2020, 53, 812-821.

(14) Pan, X.; Ding, C.; Zhang, Z.; Ke, H.; Cheng, G. Functional porous organic polymer with high $\mathrm{S}$ and $\mathrm{N}$ for reversible iodine capture. Microporous Mesoporous Mater. 2020, 300, 110161.

(15) Puthiaraj, P.; Kim, H. S.; Yu, K.; Ahn, W.-S. Triphenylaminebased covalent imine framework for $\mathrm{CO}_{2}$ capture and catalytic conversion into cyclic carbonates. Microporous Mesoporous Mater. 2020, 297, 110011.

(16) Deng, H.; Zhang, B.; Xu, Y.; Zhang, Y.; Huo, J.; Zhang, L.; Chang, G. A simple approach to prepare isoxazoline-based porous polymer for the highly effective adsorption of 2,4,6-trinitrotoluene (TNT): Catalyst-free click polymerization between an in situ generated nitrile oxide with polybutadiene. Chem. Eng. J. 2020, 393, 124674.

(17) Mo, C.; Muhammad, F.; Saba, A.; Song, J.; Wang, X.; Tian, Y.; Ding, S.; Zhu, G. Hydroxyl porous aromatic frameworks for efficient adsorption of organic micropollutants in water. RSC Adv. 2020, 10, 26335-26341.

(18) Song, Y.; Zhang, D.; Hao, L.; Wang, C.; Wu, Q.; Wang, Z. Green synthesis of o-hydroxyazobenzene porous organic polymer forefficient adsorption of aromatic compounds. J. Chromatogr. A 2019, 1583, 39-47. 
(19) Bera, R.; Ansari, M.; Alam, A.; Das, N. Triptycene, Phenolic$\mathrm{OH}$, and Azo-Functionalized Porous Organic Polymers: Efficient and Selective $\mathrm{CO}_{2}$ Capture. ACS Appl. Polym. Mater. 2019, 1, 959-968.

(20) Huang, L.; He, M.; Chen, B.; Cheng, Q.; Hu, B. Facile Green Synthesis of Magnetic Porous Organic Polymers for Rapid Removal and Separation of Methylene Blue. ACS Sustainable Chem. Eng. 2017, 5, 4050-4055.

(21) Chandra, S.; Kundu, T.; Kandambeth, S.; BabaRao, R.; Marathe, Y.; Kunjir, S. M.; Banerjee, R. Phosphoric Acid Loaded Azo $(-\mathrm{N}=\mathrm{N}-)$ Based Covalent Organic Framework for Proton Conduction. J. Am. Chem. Soc. 2014, 136, 6570-6573.

(22) Li, B.; Guo, J.; Lv, K.; Fan, J. Adsorption of methylene blue and $\mathrm{Cd}(\mathrm{II})$ onto maleylated modified hydrochar from water. Environ. Pollut. 2019, 254, 113014.

(23) Luo, X.-P.; Fu, S.-Y.; Du, Y.-M.; Guo, J.-Z.; Li, B. Adsorption of methylene blue and malachite green from aqueous solution by sulfonic acid group modified MIL-101. Microporous Mesoporous Mater. 2017, 237, 268-274.

(24) Li, X.; Cui, Y.-Y.; Chen, Y.-J.; Yang, C.-X.; Yan, X.-P. Facile synthesis of dual-functionalized microporous organic network for efficient removal of cationic dyes from water. Microporous Mesoporous Mater. 2020, 296, 110013.

(25) Zhou, Y.; Qin, L.; Wu, M.-K.; Han, L. A bifunctional anionic metal-organic framework: eversible photochromism and selective adsorption of methylene blue. Cryst. Growth Des. 2018, 18, 57385744.

(26) Baraka, A. Adsorptive removal of tartrazine and methylene blue from wastewater using elamine-formaldehyde-tartaric acid resin (and a discussion about pseudo second order model). Desalin. Water Treat. 2012, 44, 128-141.

(27) Murugesan, A.; Divakaran, M.; Raveendran, P.; Nitin Nikamanth, A. B.; Thelly, K. J. An Eco-friendly Porous Poly(imideether)s for the Efficient Removal of Methylene Blue: Adsorption Kinetics, Isotherm, Thermodynamics and Reuse Performances. J. Polym. Environ. 2019, 27, 1007-1024.

(28) Huo, J.; Luo, B.; Chen, Y. Crystalline Covalent Organic Frameworks from Triazine Nodes as Porous Adsorbents for Dye Pollutants. ACS Omega 2019, 4, 22504-22513.

(29) Huang, L.; Shuai, Q.; Hu, S. Tannin-based magnetic porous organic polymers as robust scavengers for methylene blue and lead ions. J. Cleaner Prod. 2019, 215, 280-289.

(30) Chen, X.-q.; Li, B.; Shen, Y.; Guo, J.-Z. Facile Synthesis of Calcite-Impregnated Hydrochar with High Sorption Capacity for $\mathrm{Cu}$ (II) from Aqueous Solution. ACS Omega 2019, 4, 15022-15029.

(31) Pan, X.; Qin, X.; Zhang, Q.; Ge, Y.; Ke, H.; Cheng, G. N- and S-rich covalent organic framework for highly efficient removal of indigo carmine and reversible iodine capture. Microporous Mesoporous Mater. 2020, 296, 109990.

(32) Liu, J.-L.; Qian, W.-C.; Guo, J.-Z.; Shen, Y.; Li, B. Selective removal of anionic and cationic dyes by magnetic Fe3O4-loaded amine-modified hydrochar. Bioresour. Technol. 2021, 320, 124374.

(33) Shen, Y.; Guo, J.-Z.; Bai, L.-Q.; Chen, X.-Q.; Li, B. High effective adsorption of $\mathrm{Pb}$ (II) from solution by biochar derived from torrefaction of ammonium persulphate pretreated bamboo. Bioresour. Technol. 2021, 323, 124616.

(34) Li, B.; Zheng, J.-Q.; Guo, J.-Z.; Dai, C.-Q. A novel route to synthesize MOFs-derived mesoporous dawsonite and application in elimination of $\mathrm{Cu}$ (II) from wastewater. Chem. Eng. J. 2020, 383, 123174 . 